\title{
Minimally Invasive Transforaminal Lumbar Interbody Fusion for Lumbar Disc Lesion with Modic Changes
}

Yasuhito Kaneko', Ken Ishii ${ }^{2 *}$, Masaya Nakamura², Takahiro Koyanagi ${ }^{3}$ and Morio Matsumoto

${ }^{1}$ Department of Orthopaedic Surgery, Saitama City Hospital, Saitama, Japan, Keio Spine Research Group (KSRG), The Society for Minimally Invasive spine Stabilization (MISt), Japan

${ }^{2}$ Department of Orthopaedic Surgery, School of Medicine, Keio University, Tokyo, Japan, Keio Spine Research Group (KSRG), The Society for Minimally Invasive spine Stabilization (MISt), Japan

${ }^{3}$ Department of Orthopaedic Surgery, Kawasaki Municipal Kawasaki Hospital, Keio Spine Research Group (KSRG), Japan

\begin{abstract}
Purpose: This study was conducted to assess short- to mid-range clinical outcomes of minimally invasive transforaminal lumbar interbody fusion (MIS-TLIF) for patients with severe low back pain caused by intervertebral disc degeneration showing Modic changes on MRI.
\end{abstract}

Methods: Thirty-five consecutive patients (mean age: 48.6 years) who underwent single-level MIS-TLIF to treat severe low back pain with Modic changes on MRI were included. Diagnoses were based on temporary pain relief after an intradiscal anesthetic injection, selective nerve blocking, or both. The mean follow-up period was 18 months. Japanese Orthopaedic Association (JOA) scores (29 possible points), JOA-score recovery rates (RR), Visual Analog Pain Scale (VAS) scores for low back pain, and the Oswestry Disability Index (ODI) were evaluated.

Results: The average JOA score improved significantly, from $14.8 \pm 3.6$ preoperatively to $26.9 \pm 1.6$ at the final follow-up $(P<0.01)$. The average JOA-score RR was $84.8 \pm 11.7 \%$. Significant improvements were obtained in the average VAS scores for low back pain (preoperative, $7.8 \pm 1.9$; final follow-up, $1.5 \pm 0.7$; $\mathrm{P}<0.01$ ) and ODI (preoperative, $57.9 \pm 16.1$; final follow-up, $13.0 \pm 8.8 ; \mathrm{P}<0.01$ ). Modic type 1 changes were observed in 12 patients, and type 2 changes in 23 patients. The JOA-score RR did not differ significantly between patients with Modic type 1 and type $2(85.7 \%$ and $84.1 \%$, respectively).

Conclusions: MIS-TLIF, which is less damaging to the paraspinal muscles than conventional approaches, is a reasonable surgical option for lumbar disc lesion with Modic type 1 and 2 changes.

Keywords: Lumbar disc lesion; Modic changes; Minimally invasive transforaminal lumbar interbody fusion (MIS-TLIF)

\section{Introduction}

Since 1988, when Modic et al., [1] described changes in MRI signal intensity, termed Modic changes, in the vertebral bone extending from the vertebral endplate, various papers have commented on the correlation of these changes with the low back pain [2,3], epidemiology $[3,4]$, pathophysiology $[5,6]$, natural history $[7,8]$, and other aspects of this pathological condition. However, the treatment for patients with Modic changes is not well described and remains controversial, especially regarding surgical options, because the severity of low back pain in many patients is often not constant [9].

Theoretically, anterior lumbar interbody fusion (ALIF) should be the first-line surgical option for lumbar disc lesions associated with Modic changes. However, conventional ALIF carries potentially serious risks, including large vessel injury, abdominal wall weakness or herniation, and dry ejaculation [10]. Therefore, severe back pain with Modic changes has generally been treated by conventional posterior surgeries, including posterior lumbar interbody fusion (PLIF) or posterolateral fusion (PLF) [11,12]. Although some studies have reported that low back pain is more strongly associated with Modic type 1 (M1) than type 2 (M2) changes, Jensen et al. found no significant difference in the low back pain associated with different types of Modic change in their systematic review $[3,13,14]$. Other studies have reported that the clinical outcomes of conventional posterior lumbar fusion were better for patients with M1 changes than those with M2 changes [11,12]; this might have been related to the degree of persistent postoperative back pain due to paraspinal muscle damage caused by the invasive conventional approach.

Recently, various devices designed for minimally invasive spinal stabilization have made it possible to reduce damage to the paraspinal muscles [15-19]. To our knowledge, there are no reports on the efficacy of minimally invasive spine surgery for patients with Modic changes. In the present study, we hypothesized that minimally invasive transforaminal lumbar interbody fusion (MIS-TLIF) using percutaneous pedicle-screw devices would be an effective surgical option for patients with severe low back pain caused by intervertebral disc degeneration with Modic changes on MRI.

\section{Materials and Methods}

\section{Patients}

This study evaluated 35 consecutive patients, 25 men and 10 women, who underwent single-level MIS-TLIF between July 2007 and October 2011. The mean age was 48.6 years (23-74 years). The mean follow-up period was 18 months (10-41 months). The spine was fused at L4-5 in 17 patients, L5-S1 in 15 and L3-4 in 3 (Table 1). All the patients had a history of severe low back pain that was not relieved after at least 3 months of conservative treatment (e.g. avoiding lumbar loads, using a lumbar corset or brace, or taking painkillers), with evident M1 or M2 changes on MR images; all patients experienced temporary relief from low back pain when treated by intradiscal anaesthetic injection

*Corresponding author: Ken Ishii, Department of Orthopaedic Surgery, Keio University School of Medicine, Shinanomachi 35, Shinjuku-ku, Tokyo, 160-8582 Japan, Tel: 81-3-5363-3812; Fax: 81-3-3353-6597; E-mail: keni8888@z7.keio.jp

Received February 08, 2016; Accepted February 19, 2016; Published February 21, 2016

Citation: Kaneko Y, Ishii K, Nakamura M, Koyanagi T, Matsumoto M (2016) Minimally Invasive Transforaminal Lumbar Interbody Fusion for Lumbar Disc Lesion with Modic Changes. J Spine 5: 289. doi:10.4172/2165-7939.1000289

Copyright: @ 2016 Kaneko Y, et al. This is an open-access article distributed under the terms of the Creative Commons Attribution License, which permits unrestricted use, distribution, and reproduction in any medium, provided the original author and source are credited. 
at the affected level. Patients were excluded from the study if they had symptoms at two or more levels, disc extrusion with symptomatic root compression, spondylolysis or spondylolisthesis, an active infection or tumour, or a history of psychiatric malady, or if the low back pain was related to a work- or traffic-related injury. This clinical study was approved by the ethics committees of the authors' institutions.

\section{MR imaging}

MR images were obtained with a $1.5 \mathrm{~T}$ magnetic resonance unit (Philips Achieva, the Netherlands) using the following imaging protocol: sagittal T1-weighted (FOV 300, TR 400-800, TE 12, matrix $400 \times 240$, slice thickness $4 \mathrm{~mm}$, and number of slices 12 ); sagittal T2weighted (FOV 300, TR 3000, TE 100, matrix $400 \times 231$, slice thickness $4 \mathrm{~mm}$, and number of slices 12); and axial T2 (FOV $200 \times 181$, TR3474, TE100, matrix $336 \times 211$, slice thickness $4 \mathrm{~mm}$, and number of slices $5 \times$ 3). Signal intensity changes involving the bone marrow of the adjacent vertebral body were classified as described by Modic et al. [1], into Modic type 1 (M1, hypointense on T1 and hyperintense on T2), type 2 (M2, hyperintense on both $\mathrm{T} 1$ and $\mathrm{T} 2$ ), or type 3 (M3, hypointense on both T1 and T2). If signals in the T1-weighted sequences were mixed, the lesion was classified as M1 or M2 based on the sagittal slice with the largest intensity change in the vertebral endplate: patients who showed a broader hypointense area were placed in the M1 group, and those who showed a broader hyperintense area were placed in the M2 group. Similarly, patients with mixed M1/3 and M2/3 types were placed in the $\mathrm{M} 1$ and M2 groups, respectively.

\section{Surgical techniques}

Patients were placed under general anaesthesia, and were placed in the prone position on the radiolucent frame. The anatomical midline, the transverse line parallel to the affected disc level, and $3-\mathrm{cm}$ longitudinal incision lines on both sides (approximately $4-5 \mathrm{~cm}$ lateral to the midline) were marked on the skin using fluoroscopic guidance. The symptomatic side was typically chosen as the approach and decompression side. After making the skin incision, a Quadrant retractor system $(22 \mathrm{~mm}$ diameter, expandable, Medtronic Inc., Memphis, TN) or Endoscope Spinal System (ESD; $18 \mathrm{~mm}$ diameter, Tanaka Medical instruments Co., Ltd., Tokyo) was placed onto the lamina-facet junction at the relevant level through the multifidus muscle, which was minimally split at the medial side. The procedure was performed under direct vision. Total facetectomy was performed using osteotomes and Kerrison rongeurs, followed by resection of the yellow ligament. The disc and the cartilaginous endplate were meticulously removed, interbody fusion was performed by packing local bone graft obtained from the removed facet and inserting two PEEK cages (Capstone, Medtronic Inc., USA or

\begin{tabular}{|l|c|c|c|}
\hline & M1 & M 2 & Total \\
\hline No. of patients & 12 & 23 & 35 \\
\hline Mean age (years) & $50.1 \pm 15.6$ & $47.9 \pm 12.0$ & $48.6 \pm 13.0$ \\
\hline Gender (male/female) & $9 / 3$ & $15 / 8$ & $24 / 11$ \\
\hline Height (cm) & $164.4 \pm 8.8$ & $165.0 \pm 8.5$ & $164.8 \pm 8.5$ \\
\hline Body weight (kg) & $66.7 \pm 12.0$ & $66.6 \pm 9.6$ & $66.6 \pm 10.2$ \\
\hline Body mass index & $24.9 \pm 5.3$ & $24.4 \pm 2.7$ & $24.6 \pm 3.7$ \\
\hline $\begin{array}{l}\text { Follow-up period } \\
\text { (months) }\end{array}$ & $14.6 \pm 10.1$ & $18.8 \pm 10.0$ & $17.5 \pm 10.1$ \\
\hline Level of fusion & \multicolumn{3}{|c|}{} \\
\hline L3-4 & 5 & 1 & 3 \\
\hline L4-5 & 5 & 10 & 17 \\
\hline L5-S1 & 5 & & 15 \\
\hline
\end{tabular}

M1 Modic type 1 change, M2 Modic type 2 change

Table 1: Demographic data of the study population.
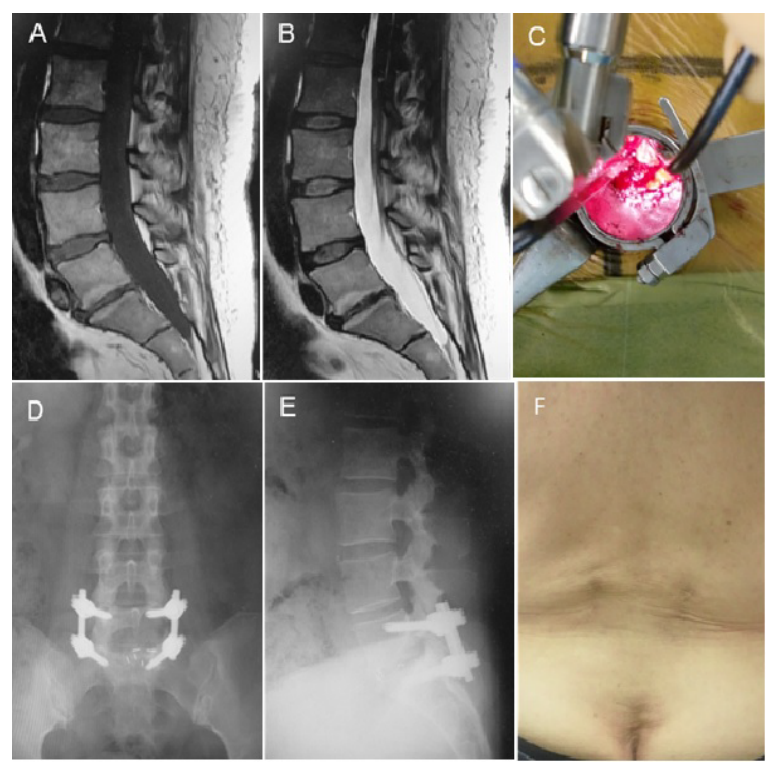

Figure 1: $(A, B)$ Preoperative MR images of a 53-year-old male who presented with persistent low back pain associated with a lumbar disc lesion exhibiting Modic type 2 change on MRI. (C) View under an ESD tubular retractor with attached light cables. (D) Postoperative anteroposterior and (E) lateral radiographs. (F) The skin incision for MIS-TLIF.

OIC, Stryker, USA), and the retractor was removed. Because endplate degeneration, including Modic changes, subchondral bone sclerosis, or cyst formation, can raise the risk of non-union, the endplate was meticulously prepared prior to grafting the bone. Within the same incisions, the longissimus muscles were split and bilateral pedicle screws were placed over a guide wire under fluoroscopy. A representative case is shown in Figure 1.

All patients began walking on the day after surgery, and wore a hard corset-style brace for three months.

\section{Assessment}

We retrospectively collected the following clinical data for each patient: age, gender, height, body weight, type of Modic change, level of fusion, operating time, estimated blood loss, and perioperative complications. Back and leg pain was assessed based on preoperative and follow-up Japanese Orthopaedic Association (JOA) scores, recovery rate (RR) of JOA score [20], Visual Analog Scale (VAS) scores for low back pain, and the Oswestry disability index (ODI; version 2.0). Definitive fusion was identified by less than $3^{\circ}$ segmental movement on flexion-extension plain X-rays and the formation of trabecular bony bridges between contiguous vertebral bodies at the relevant level on CT.

\section{Statistical analysis}

Statistical analyses were performed with Dr. SPSS II for Windows (SPSS Japan Inc., Tokyo, Japan). The Mann-Whitney $U$ test was used to compare continuous variables and clinical outcomes between the patients showing M1 changes (M1 group) and M2 changes (M2 group) on MR images. $P$ values smaller than 0.05 were considered statistically significant.

\section{Results}

The average operating time was $157.1 \pm 48.0$ minutes (range 83300 minutes); the average estimated blood loss was $139.8 \pm 195.0 \mathrm{ml}$ (range, 15-1085 ml). Complications included transient leg pain due to epidural hematoma (1 patient) and superficial wound infection (1 


\begin{tabular}{|c|c|c|c|}
\hline & M1 (n=12) & M2 $(n=23)$ & Total $(n=35)$ \\
\hline Operating time (min) & $166.5 \pm 40.0$ & $145.1 \pm 33.4$ & $157.1 \pm 48.0$ \\
\hline $\begin{array}{l}\text { Estimated blood loss } \\
(\mathrm{ml})\end{array}$ & $140.4 \pm 143.9$ & $113 \pm 101.7$ & $139.8 \pm 195$ \\
\hline $\begin{array}{l}\text { Perioperative } \\
\text { complication (No. of } \\
\text { patients) }\end{array}$ & $\begin{array}{l}\text { Superficial wound } \\
\text { infection (1) }\end{array}$ & $\begin{array}{l}\text { Epidural } \\
\text { hematoma (1) }\end{array}$ & \\
\hline \multicolumn{4}{|l|}{ JOA score (0-29 points) } \\
\hline Preoperative & $13.7 \pm 4.1$ & $15.3 \pm 3.4$ & $14.8 \pm 3.6$ \\
\hline Final follow-up & $26.8 \pm 1.9$ & $26.9 \pm 1.4$ & $26.9 \pm 1.6$ \\
\hline $\begin{array}{l}\text { Recovery rate of JOA } \\
\text { score }(\%)\end{array}$ & $85.7 \pm 11.5$ & $84.1 \pm 11.7$ & $84.8 \pm 11.7$ \\
\hline \multicolumn{4}{|l|}{ VAS for low back pain } \\
\hline Preoperative & $8.0 \pm 1.6$ & $7.7 \pm 2.1$ & $7.8 \pm 1.9$ \\
\hline Final follow-up & $1.5 \pm 0.5$ & $1.5 \pm 0.7$ & $1.5 \pm 0.7$ \\
\hline \multicolumn{4}{|c|}{ Oswestry disability index } \\
\hline Preoperative & $62.6 \pm 13.0$ & $55.8 \pm 17.2$ & $57.9 \pm 16.1$ \\
\hline Final follow-up & $12.5 \pm 6.6$ & $13.2 \pm 9.8$ & $13.0 \pm 8.8$ \\
\hline
\end{tabular}

Values are mean \pm standard deviation. M1: Modic type 1 change, M2: Modic type 2 change, JOA: Japanese Orthopaedic Association, VAS: Visual Analog Scale; Recovery rate $(\%)=($ postoperative $\mathrm{JOA}$ score - preoperative JOA score $) \times 100 /$ (29 - preoperative JOA score)

Table 2: Comparison of clinical results.

patient); both cases were resolved with conservative treatment. There were no cases of radiological non-union or revision surgery in this series. The average JOA score improved significantly, from $14.8 \pm 3.6$ points (pts) preoperatively to $26.9 \pm 1.6$ pts at the final follow-up ( $P$ $<0.01)$. The average JOA-score RR at the final follow-up was $84.8 \pm$ $11.7 \%$. Significant improvements were obtained in VAS scores for low back pain (preoperative, $7.8 \pm 1.9$; follow-up, $1.5 \pm 0.7 ; P<0.01$ ) and ODI (preoperative, $57.9 \pm 16.1$; follow-up, $13.0 \pm 8.8$ pts; $P<0.01$ ).

The M1 and M2 groups included 12 and 23 patients, respectively. No patients with M3 changes were included in this series. There were no statistically significant differences in background data between the two groups (Table 1). Likewise, there were no significant differences between the groups in preoperative and follow-up JOA scores (M1: 13.7 \pm 4.1 to $26.8 \pm 1.9$ pts; M2: $15.3 \pm 3.4$ to $26.9 \pm 1.4$ pts), VAS low back pain scores (M1: $8.0 \pm 1.6$ to $1.5 \pm 0.5$; M2: $7.7 \pm 2.1$ to $1.5 \pm 0.7$ ), or ODI (M1: $62.6 \pm 13.0$ to $12.5 \pm 6.6$ pts; M2: $55.8 \pm 17.2$ to $13.2 \pm 9.8$ pts), or in JOA-score RR (M1: $85.7 \pm 11.5 \%$; M2: $84.1 \pm 11.7 \%$ ) (Table 2).

\section{Discussion}

First-line choices for chronic low back pain due to lumbar disc lesions with Modic changes include conservative treatments such as avoiding lumbar loads, using a lumbar corset or brace, or taking painkillers. If the condition does not respond to these treatments, the patient may benefit from intradiscal steroid injections [19]. When all conservative treatments have failed, patients have been treated by ALIF, PLIF, and/or PLF to stabilize the damaged segments of the spine. However, conventional ALIF can have severe complications [10]. PLIF and PLF can also cause residual low back pain from "fusion disease", which results from muscle stripping and retraction during conventional-approach surgeries [15,21-24].

The MIS-TLIF procedure was developed to minimize soft tissue injury and approach-related morbidity [15,21-24]. As reported previously, MIS-TLIF has its own drawbacks, including the learning curve for the specific techniques, the intraoperative radiation exposure, and the expensive instruments and equipment used [15]. On the other hand, MIS-TLIF can be performed with less blood loss, less postoperative pain, and less muscle damage than conventional surgeries, and a shorter hospital stay and rehabilitation time compared to conventional procedures [21,23-24]. In the present study, the shortto mid-range clinical outcomes of MIS-TLIF for lumbar disc lesions with Modic changes were favorable, with improvement in the scores for JOA, ODI, and VAS for low back pain. To our knowledge, this is the first study to report the effectiveness of MIS-TLIF for lumbar disc lesions with Modic changes on MR images. In contrast to previous reports $[11,12]$, satisfactory outcomes were obtained with MIS-TLIF even for patients with M2 changes; this may be attributable to the less invasive treatment of the paraspinal muscles in the MIS procedures used in this series.

Minimally invasive ALIF techniques, including XLIF and DLIF, followed by percutaneous pedicle-screw placement might be another favourable option when decompression of posterior neural elements is not necessary, as with the patients in this study. However, this technique has potentially serious complications, such as great vessel injury or lumbar nerve injury, especially at L4-5. This approach has another drawback; the iliac crest blocks access to the L5-S1 level [16]. MIS-TLIF may be safer and more useful than X/DLIF because it enables not only direct visualisation and protection of the nerve root during procedures within the intervertebral space, but also autologous local bone graft is sufficient, without the need for synthetic bone graft materials or iliac crest bone graft. In addition, MIS-TLIF can be performed at any level of the lumbar spine, including L5-S1. However, since adhesions of the anterior epidural space were frequently seen in our series, even in the primary operation, care should be taken to avoid any dural laceration or nerve root injury.

In this study, we demonstrated that MIS-TLIF is useful for patients with severe low back pain caused by intervertebral disc degeneration with Modic changes. Since our study did not include a control group treated by conventional TLIF, ALIF, or X/DLIF, further prospective studies may be needed to confirm the results obtained in this retrospective study.

In conclusion, this study showed that short- and mid-range clinical outcomes of MIS-TLIF for patients with intractable low back pain associated with Modic changes were favorable for patients with type 1 or type 2 changes. Because it is less destructive to paraspinal muscles than conventional approaches, MIS-TLIF can be a useful surgical option for those pathological conditions.

\section{References}

1. Modic MT, Steinberg PM, Ross JS, Masaryk TJ, Carter JR (1988) Degenerative disk disease: assessment of changes in vertebral body marrow with MR imaging. Radiology 166: 193-199.

2. Kjaer P, Korsholm L, Bendix T, Sorensen JS, Leboeuf-Yde C (2006) Modic changes and their associations with clinical findings. Eur Spine J 15: 13121319 .

3. Jensen TS, Karppinen J, Sorensen JS, Niinimäki J, Leboeuf-Yde C (2008) Vertebral endplate signal changes (Modic change): a systematic literature review of prevalence and association with non-specific low back pain. Eur Spine J 17: 1407-1422.

4. Albert HB, Briggs AM, Kent P, Byrhagen A, Hansen C, et al. (2011) The prevalence of MRI-defined spinal pathoanatomies and their association with modic changes in individuals seeking care for low back pain. Eur Spine J 20 : 1355-1362.

5. Ohtori S, Inoue G, Ito T, Koshi T, Ozawa T, et al. (2006) Tumor necrosis factorimmunoreactive cells and PGP 9.5-immunoreactive nerve fibers in vertebra endplates of patients with discogenic low back Pain and Modic Type 1 or Type 2 changes on MRI. Spine (Phila Pa 1976) 31: 1026-1031.

6. Karppinen J, Solovieva S, Luoma K, Raininko R, Leino-Arjas P, et al. (2009) Modic changes and interleukin 1 gene locus polymorphisms in occupational cohort of middle-aged men. Eur Spine J 18: 1963-1970.

7. Jensen TS, Bendix T, Sorensen JS, Manniche C, Korsholm L, et al. (2009) 
Citation: Kaneko Y, Ishii K, Nakamura M, Koyanagi T, Matsumoto M (2016) Minimally Invasive Transforaminal Lumbar Interbody Fusion for Lumbar Disc Lesion with Modic Changes. J Spine 5: 289. doi:10.4172/2165-7939.1000289

Characteristics and natural course of vertebral endplate signal (Modic) changes in the Danish general population. BMC Musculoskelet Disord 10: 81.

8. Hutton MJ, Bayer JH, Powell JM (2011) Modic vertebral body changes: the natural history as assessed by consecutive magnetic resonance imaging. Spine (Phila Pa 1976) 36: 2304-2307.

9. Weishaupt D, Zanetti M, Hodler J, Min K, Fuchs B, et al. (2001) Painful Lumbar Disk Derangement: Relevance of Endplate Abnormalities at MR Imaging. Radiology 218: 420-427.

10. Sasso RC, Best NM, Mummaneni PV, Reilly TM, Hussain SM (2005) Analysis of operative complications in a series of 471 anterior lumbar interbody fusion procedures. Spine (Phila Pa 1976) 30: 670-674.

11. Esposito P, Pinheiro-Franco JL, Froelich S, Maitrot D (2006) Predictive value of MRI vertebral end-plate signal changes (Modic) on outcome of surgically treated degenerative disc disease. Results of a cohort study including 60 patients. Neurochirurgie 52: 315-322.

12. Chataigner $\mathrm{H}$, Onimus $\mathrm{M}$, Polette $A$ (1998) [Surgery for degenerative lumbar disc disease. Should the black disc be grafted?]. Rev Chir Orthop Reparatrice Appar Mot 84: 583-589

13. Toyone T, Takahashi K, Kitahara H, Yamagata M, Murakami M, et al. (1994) Vertebral bone-marrow changes in degenerative lumbar disc disease. An MRI study of 74 patients with low back pain. J Bone Joint Surg Br 76: 757-764.

14. Kuisma M, Karppinen J, Niinimäki J, Ojala R, Haapea M, et al. (2007) Modic changes in endplates of lumbar vertebral bodies: prevalence and association with low back and sciatic pain among middle-aged male workers. Spine (Phila Pa 1976) 32: 1116-1122.

15. Foley KT, Holly LT, Schwender JD (2003) Minimally invasive lumbar fusion. Spine (Phila Pa 1976) 28: S26-35.
16. Ozgur BM, Aryan HE, Pimenta L, Taylor WR (2006) Extreme Lateral Interbody Fusion (XLIF): a novel surgical technique for anterior lumbar interbody fusion. Spine J 6: 435.443

17. Theodorou DJ, Theodorou SJ, Duncan TD, Garfin SR, Wong WH (2002) Percutaneous balloon kyphoplasty for the correction of spinal deformity in painful vertebral body compression fractures. Clin Imaging 26: 1-5.

18. Zucherman JF, Hsu KY, Hartjen CA, Mehalic TF, Implicito DA, et al. (2004)A prospective randomized multi-center study for the treatment of lumbar spinal stenosis with the $X$ STOP interspinous implant: 1-year results. Eur Spine J 13: 22-31.

19. Fayad F, Lefevre-Colau MM, Rannou F, Quintero N, Nys A, et al. (2007) Relation of inflammatory modic changes to intradiscal steroid injection outcome in chronic low back pain. Eur Spine J 16: 925-931.

20. Hirabayashi K, Miyakawa J, Satomi K, Maruyama T, Wakano K (1981) Operative results and postoperative progression of ossification among patients with ossification of posterior longitudinal ligament. Spine 6: 354-364.

21. Isaacs RE, Podichetty VK, Santiago P, Sandhu FA, Spears J, et al. (2005) Minimally invasive microendoscopy-assisted transforaminal lumbar interbody fusion with instrumentation. J Neurosurg Spine 3: 98-105.

22. Schwender JD, Holly LT, Rouben DP, Foley KT (2005) Minimally invasive transforaminal lumbar interbody fusion (TLIF): technical feasibility and initial results. J Spinal Disord Tech 18 Suppl: S1-6.

23. Scheufler KM, Dohmen H, Vougioukas VI (2007) Percutaneous transforaminal lumbar interbody fusion for the treatment of degenerative lumbar instability. Neurosurgery 60: 203-212.

24. Peng CW, Yue WM, Poh SY, Yeo W, Tan SB (2009) Clinical and radiological outcomes of minimally invasive versus open transforaminal lumbar interbody fusion. Spine (Phila Pa 1976) 34: 1385-1389. 